\title{
GLACE: The Global Land-Atmosphere Coupling Experiment. Part II: Analysis
}

\author{
Zhichang Guo, ${ }^{a}$ Paul A. Dirmeyer, ${ }^{\mathrm{a}}$ Randal D. Koster, ${ }^{\mathrm{b}}$ Gordon Bonan, ${ }^{\mathrm{c}}$ Edmond Chan, ${ }^{\mathrm{d}}$ \\ Peter Cox,${ }^{\mathrm{e}}$ C. T. Gordon, ${ }^{\mathrm{f}}$ Shinjiro Kanae, ${ }^{\mathrm{g}}$ Eva Kowalczyk, ${ }^{\mathrm{h}}$ David Lawrence, ${ }^{\mathrm{i}}$ Ping Liu, ${ }^{\mathrm{j}}$ \\ Cheng-Hsuan Lu, ${ }^{\mathrm{k}}$ Sergey Malyshev, ${ }^{1}$ Bryant McAvaney, ${ }^{\mathrm{m}} \mathrm{J}$. L. McGregor,${ }^{\mathrm{f}}$ Ken Mitchell, ${ }^{\mathrm{k}}$ \\ David Mocko, ${ }^{\mathrm{j}}$ Taikan OKi, ${ }^{\mathrm{n}}$ Keith W. Oleson, ${ }^{\mathrm{c}}$ Andrew Pitman, ${ }^{\mathrm{o}}$ Y. C. Sud, ${ }^{\mathrm{b}}$ \\ Christopher M. TAylor, ${ }^{\mathrm{p}}$ Diana Verseghy, ${ }^{\mathrm{d}}$ Ratko Vasic, ${ }^{\mathrm{q}}$ Yongkang Xue, ${ }^{\mathrm{q}}$ AND \\ TOMOHITO YAMADA ${ }^{\mathrm{n}}$ \\ ${ }^{a}$ Center for Ocean-Land-Atmosphere Studies, Calverton, Maryland \\ ${ }^{\mathrm{b}}$ NASA Goddard Space Flight Center, Greenbelt, Maryland \\ ${ }^{\mathrm{c}}$ National Center for Atmospheric Research, Boulder, Colorado \\ ${ }^{\mathrm{d}}$ Meteorological Service of Canada, Toronto, Ontario, Canada \\ ${ }^{\mathrm{e}}$ Centre for Ecology and Hydrology, Dorset, Dorset, United Kingdom \\ ${ }^{\mathrm{f}}$ Geophysical Fluid Dynamics Laboratory, Princeton, New Jersey \\ ${ }^{\mathrm{g}}$ Research Institute for Humanity and Nature, Kyoto, Japan \\ ${ }^{\mathrm{h}}$ CSIRO Atmospheric Research, Aspendale, Victoria, Australia \\ ${ }^{\mathrm{i}}$ University of Reading, Reading, Berkshire, United Kingdom \\ ${ }^{\mathrm{j} S}$ Science Applications International Corporation, Beltsville, Maryland \\ ${ }^{\mathrm{k}}$ National Centers for Environmental Prediction, Camp Springs, Maryland \\ ${ }^{1}$ Princeton University, Princeton, New Jersey \\ ${ }^{\mathrm{m}}$ Bureau of Meteorology Research Centre, Melbourne, Victoria, Australia \\ ${ }^{\mathrm{n}}$ University of Tokyo, Tokyo, Japan \\ ${ }^{\circ}$ Macquarie University, North Ryde, New South Wales, Australia \\ ${ }^{\mathrm{P}}$ Centre for Ecology and Hydrology, Wallingford, Oxfordshire, United Kingdom \\ ${ }^{\mathrm{q}}$ University of California, Los Angeles, Los Angeles, California
}

(Manuscript received 5 April 2005, in final form 31 October 2005)

\begin{abstract}
The 12 weather and climate models participating in the Global Land-Atmosphere Coupling Experiment (GLACE) show both a wide variation in the strength of land-atmosphere coupling and some intriguing commonalities. In this paper, the causes of variations in coupling strength - both the geographic variations within a given model and the model-to-model differences-are addressed. The ability of soil moisture to affect precipitation is examined in two stages, namely, the ability of the soil moisture to affect evaporation, and the ability of evaporation to affect precipitation. Most of the differences between the models and within a given model are found to be associated with the first stage - an evaporation rate that varies strongly and consistently with soil moisture tends to lead to a higher coupling strength. The first-stage differences reflect identifiable differences in model parameterization and model climate. Intermodel differences in the evaporation-precipitation connection, however, also play a key role.
\end{abstract}

\section{Introduction}

Interaction between the land and atmosphere plays an important role in the evolution of weather and the generation of precipitation $(P)$. Soil moisture may be

Corresponding author address: Zhichang Guo, Center for Ocean-Land-Atmosphere Studies, 4041 Powder Mill Road, Suite 302, Calverton, MD 20705-3106.

E-mail: guo@cola.iges.org the most important state variable in this regard. Much research has been conducted on the effects of soil wetness (SW) variability on weather and climate, encompassing various observational studies (e.g., Namias 1960; Betts et al. 1996; Findell and Eltahir 2003) and theoretical treatments (e.g., Entekhabi et al. 1992; Eltahir 1998). These studies notwithstanding, the strength of the land-atmosphere interaction is tremendously difficult to measure and evaluate. Consider, for example, attempts to quantify the impact of soil mois- 
ture on precipitation through joint observations of both. Precipitation may be larger when soil moisture is larger, but this may tell us nothing, for the other direction of causality - the wetting of the soil by precipitation-almost certainly dominates the observed correlation. Global-scale or even regional-scale estimates of land-atmosphere coupling strength simply do not exist.

This difficulty motivates the use of numerical climate models to address the land-atmosphere feedback question. With such models, idealized experiments can be crafted and sensitivities carefully examined. A few recent examples include the studies of Dirmeyer (2001), Koster and Suarez (2001), Schlosser and Milly (2002), and Douville (2003).

Modeling studies, of course, are far from perfect. The ability of land states to affect atmospheric states in atmospheric general circulation models (AGCMs) is not explicitly prescribed or parameterized, but is rather a net result of complex interactions between numerous process parameterizations in the model. As a result, land-atmosphere interaction varies from model to model, and this model dependence affects AGCMbased interpretations of land use impacts on climate, soil moisture impacts on precipitation predictability, and so forth (Koster et al. 2002). The broad usage of AGCMs for such research and the need for an appropriate interpretation of model results makes a comprehensive evaluation of land-atmosphere interaction across a broad range of models necessary. The Global Land-Atmosphere Coupling Experiment (GLACE) was designed with this in mind.

In GLACE, $12 \mathrm{AGCMs}$ perform the same highly controlled numerical experiment, which is designed to characterize land-atmosphere interaction quantitatively. In GLACE, three 16-member ensembles of 3-month simulations are performed: an ensemble in which the land states of the different members vary independently and interact with the atmosphere (W), an ensemble in which the same geographically and temporally varying land states are prescribed for each member (R), and an ensemble in which only the subsurface soil moisture values are prescribed for each member (S). By quantifying the interensemble similarity of precipitation time series within each ensemble and then comparing this similarity between ensembles, we can isolate the impact of the land surface on precipitation; we can quantify the degree to which the atmosphere responds consistently to anomalies in land states. (The degree of consistent response is hereafter referred to as the "land-atmosphere coupling strength.") The companion paper (Koster et al. 2006, hereafter Part I) describes the experiment and analysis approach in detail and provides an overview of the model comparison.

Note that the focus on subsurface moisture (ensemble $\mathrm{S}$ above) is of special interest. It is well accepted that the variability of soil moisture is much slower than that of atmospheric states (Dirmeyer 1995). Hope for improving the accuracy of seasonal forecasts lies partly with the "memory" provided by soil moisture. By quantifying the impact of subsurface soil moisture on precipitation, GLACE helps evaluate a model's ability to make use of this memory in seasonal forecasts.

Part I and Koster et al. (2004) highlight "hot spots" of land-atmosphere coupling-regions of strong coupling between soil moisture and precipitation that are common to many of the AGCMs. What causes such commonalities, and how do they relate to the climatological and hydrological regime? Which aspects of the land surface and atmospheric parameterization cause the large model-to-model differences of coupling strength among the AGCMs? How are the signals that exist in the land surface states transmitted to and manifested in the atmosphere states?

Such critical questions lie at the heart of our understanding of land-atmosphere feedback. Arguably, a fully comprehensive analysis of these questions would require additional sensitivity experiments and modeldependent analysis techniques, all of which are beyond the scope of GLACE. Nevertheless, the design of GLACE and the diagnostics provided by the participants do provide powerful insight into how a soil moisture signal is translated into an evaporation signal, which in turn is translated to a precipitation signal, and how and why these translations differ among the AGCMs. Such an analysis is presented in the present paper. First, section 2 addresses the geographical patterns of coupling strength seen in the models. Section 3 then provides an analysis of intermodel differences in coupling strength. Further discussion and a summary of our findings are presented in section 4.

\section{Commonalities in coupling strength}

The multimodel synthesis used in Part I proves effective for identifying robust regions (across models) of significant soil moisture impact on precipitation and near-surface air temperature; these identified regions are less subject to problems in the process parameterizations of any of the individual model. We can apply the same multimodel analysis procedure here to the other model variables. As in Part I (see section 5), we first disaggregate variables from each model to the same fine grid, one with a resolution of $0.5^{\circ} \times 0.5^{\circ}$. We then average the results on that grid across the models, applying the same weight to each model. 
12 Model Mean $\Omega_{r}(S)-\Omega_{r}(W)$

12 Model Mean $\Omega_{\varepsilon}(S)-\Omega_{\varepsilon}(W)$

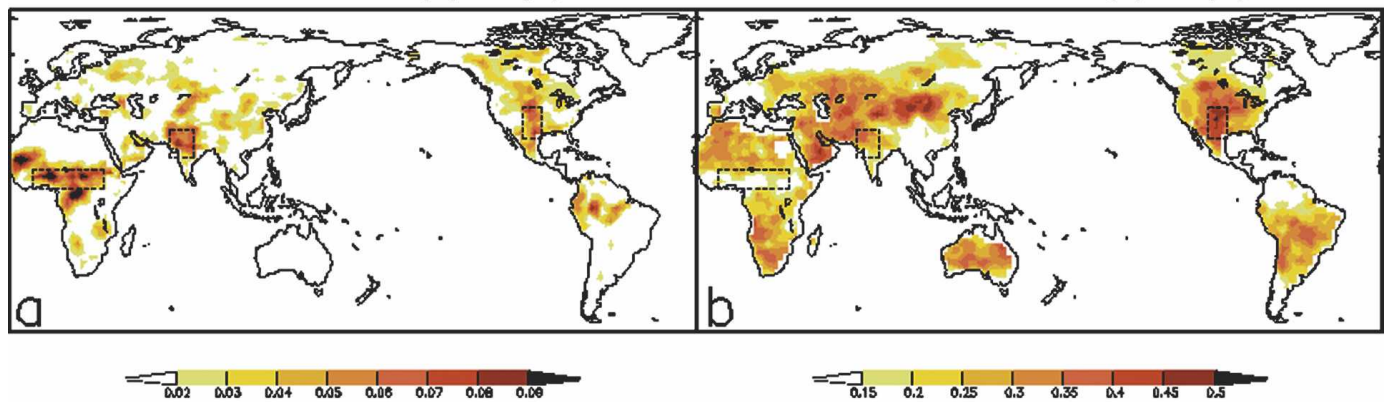

12 Model Mean $\sigma_{\mathrm{s}}(W)$

12 Model Mean $\left(\Omega_{\mathrm{s}}(S)-\Omega_{\mathrm{s}}(W)\right) * \sigma_{\mathrm{s}}(W)$

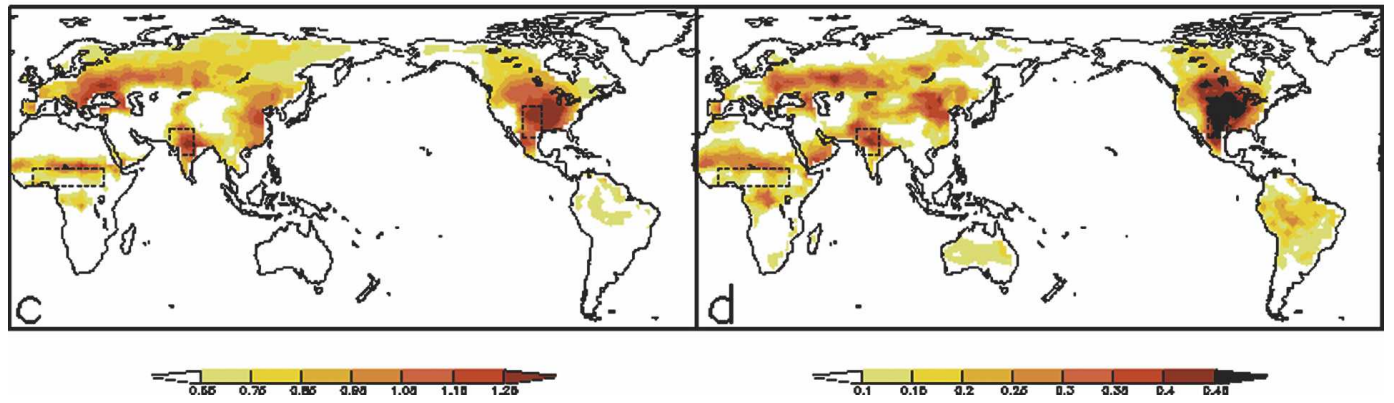

Fig. 1. Average of (a) $\Omega_{P}(\mathrm{~S})-\Omega_{P}(\mathrm{~W})$, (b) $\Omega_{E}(\mathrm{~S})-\Omega_{E}(\mathrm{~W})$, (c) standard deviation of ET, and (d) the weighted similarity diagnostic $\left[\Omega_{E}(\mathrm{~S})-\Omega_{E}(\mathrm{~W})\right] \sigma_{E}(\mathrm{~W})$ across all 12 models.

As explained in section 4 of Part I [see Eq. (2)], the variable $\Omega_{v}$ measures the degree to which the 16 time series for the variable $v$ generated by the different ensemble members are similar. Thus, $\Omega_{v}(\mathrm{~S})-\Omega_{v}(\mathrm{~W})$ or $\Omega_{v}(\mathrm{R})-\Omega_{v}(\mathrm{~W})$ are measures of the regulation of land states on the atmospheric variable $v$. As in Part I, we computed $\Omega_{v}$ and the standard deviation $\sigma_{v}$ for each model across 224 aggregated 6-day totals (16 ensemble members times 14 intervals in each simulation time series).

The upper-left panel of Fig. 1 shows the mean of $\Omega_{P}(\mathrm{~S})-\Omega_{P}(\mathrm{~W})$ for precipitation across the 12 models, that is, the model-averaged impact of subsurface soil moisture on precipitation. This figure essentially repeats the contents of the top panel of Fig. 9 from Part I. Notice that the larger soil moisture impacts on precipitation generally occur in the transition zones between humid and arid climates, such as the central Great Plains of North America, the Sahel in Africa, and the northern and western margins of the Asian monsoon regions.

How can we characterize the evaporation signal that best serves as a link between soil moisture anomalies and precipitation that best explains the geographical variations of $\Omega_{P}(\mathrm{~S})-\Omega_{P}(\mathrm{~W})$ shown in Fig. 1a, if a local soil moisture influence is assumed? In Fig. 2, we argue that such an evaporation signal (as a proxy for the full surface energy balance) must have two characteristics: it must respond similarly to soil moisture variations, and it must show wide temporal variations. The four panels show idealized evaporation time series (i.e., not from real simulations) for 16 parallel ensemble members under the following four situations: (i) a low similarity in the evaporation time series [i.e., a low value of $\left.\Omega_{E}(\mathrm{~S})-\Omega_{E}(\mathrm{~W})\right]$ and a low variability of evaporation [i.e., a low value of $\sigma_{E}(\mathrm{~W})$ ], (ii) a low similarity but a high variability of evaporation, (iii) a high similarity but a low variability of evaporation, and (iv) a high similarity and a high variability of evaporation. Clearly, cases (i) and (ii) cannot lead to a "robust" precipitation response (i.e., a similar response across ensemble members) to soil moisture, given that evaporation is the key link between the two, and evaporation itself has no robust response to soil moisture. A robust evaporation response, however, does not by itself guarantee a robust precipitation response. For case (iii), the evaporation response to soil moisture is robust, but the atmosphere would not see a strong signal at the surface because of the low evaporation variability. Only the fourth situation provides a signal for the atmosphere that is both robust and strong.

We argue that for soil moisture to affect evaporation, both $\Omega_{E}(\mathrm{~S})-\Omega_{E}(\mathrm{~W})$ and $\sigma_{E}(\mathrm{~W})$ must be suitably high. In other words, the product $\left[\Omega_{E}(\mathrm{~S})-\Omega_{E}(\mathrm{~W})\right] \sigma_{E}(\mathrm{~W})$ 

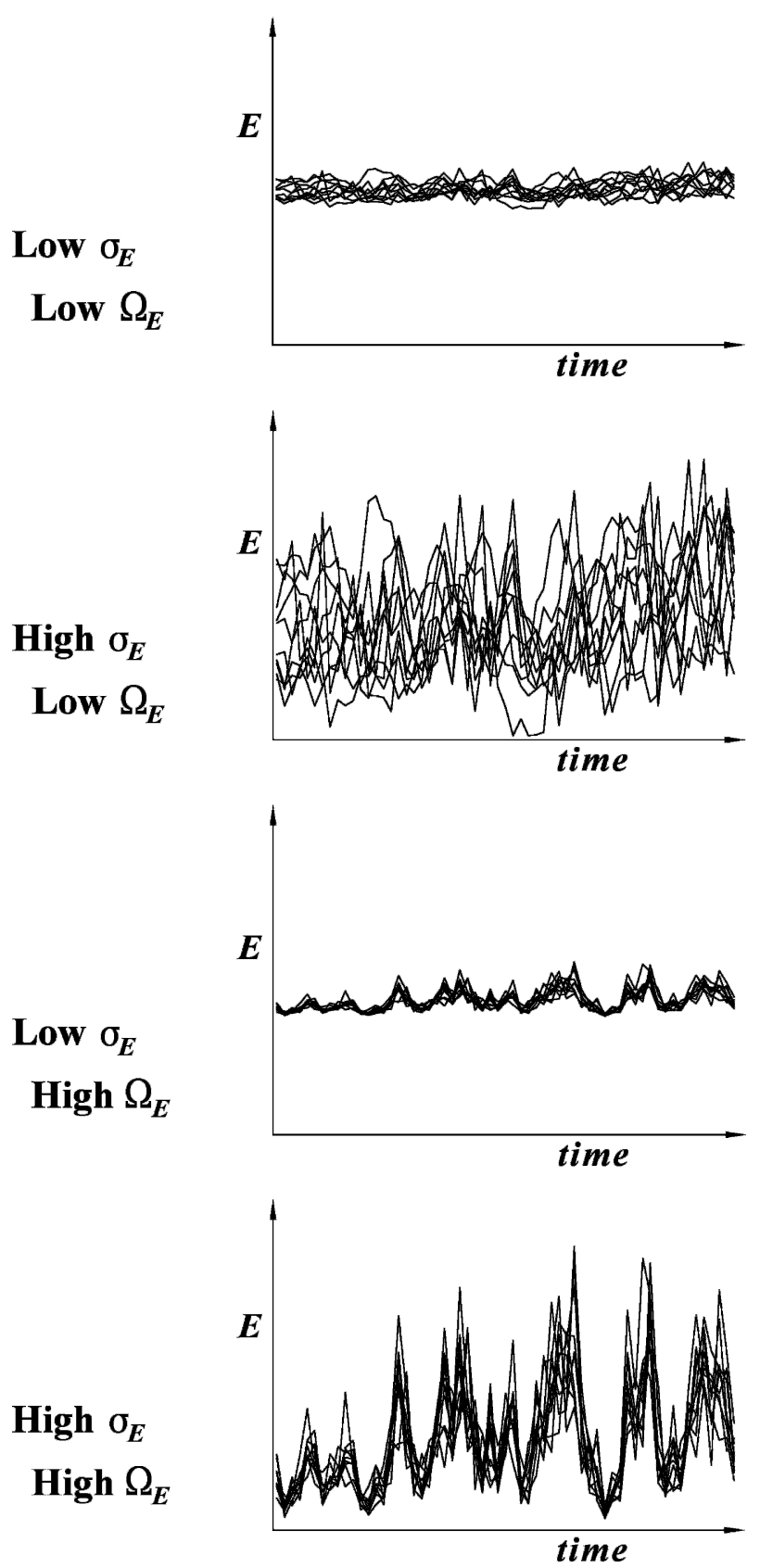

FIG. 2. Idealized time series of evaporation for different ensemble members under four situations: (i) low $\Omega_{E}$ with low $\sigma_{E}$, (ii) low $\Omega_{E}$ with high $\sigma_{E}$, (iii) high $\Omega_{E}$ with low $\sigma_{E}$, and (iv) high $\Omega_{E}$ with high $\sigma_{E}$.

must be high. We use this diagnostic product throughout this paper to characterize the ability of a local evaporation signal to support land-atmosphere feedback. [We assume here that $\sigma_{E}(\mathrm{~W})$ and $\sigma_{E}(\mathrm{~S})$ are similar; analysis of the model data confirms this.] The product proves effective for our purposes, despite being a potentially suboptimal diagnostic; it may, for example, already contain some implicit feedback information through the potential coevolution of $\sigma_{E}$ and $\sigma_{P}$, and thus it may partly reflect the character of the atmosphere and its role in feedback. Still, the other direction of causality (precipitation variability causing evaporation variability) is undoubtedly dominant, and regardless of the source of the evaporation variability, the product still serves as a characterization of the evaporation signal itself.

The upper-right panel of Fig. 1 shows the global distribution of $\Omega_{E}(\mathrm{~S})-\Omega_{E}(\mathrm{~W})$ (again, averaged across the models), and the lower-left panel shows the same for $\sigma_{E}(\mathrm{~W})$. Neither diagnostic by itself explains all of the characteristics of the distribution of $\Omega_{P}(\mathrm{~S})-\Omega_{P}(\mathrm{~W})$ (top-left panel). The lower-right panel shows the distribution of the product $\left[\Omega_{E}(\mathrm{~S})-\Omega_{E}(\mathrm{~W})\right] \sigma_{E}(\mathrm{~W})$ averaged over the 12 models (note the different scales among panels). The spatial correlation between the geographical patterns of $\Omega_{P}(\mathrm{~S})-\Omega_{P}(\mathrm{~W})$ and the product is 0.46 , which is larger than that between $\Omega_{P}(\mathrm{~S})-$ $\Omega_{P}(\mathrm{~W})$ and either factor alone [0.35 and 0.2 for $\sigma_{E}(\mathrm{~W})$ and $\Omega_{E}(\mathrm{~S})-\Omega_{E}(\mathrm{~W})$, respectively]. Of course, none of these spatial correlations is particularly large. Nevertheless, as will be shown in section 3 , the diagnostic product $\left[\Omega_{E}(\mathrm{~S})-\Omega_{E}(\mathrm{~W})\right] \sigma_{E}(\mathrm{~W})$ explains the intermodel differences in coupling strength at a given location well, much better than can either factor could alone.

The scatterplots in Fig. 3 illustrate further the control of hydrological regime on the product $\left[\Omega_{E}(\mathrm{~S})-\right.$ $\left.\Omega_{E}(\mathrm{~W})\right] \sigma_{E}(\mathrm{~W})$. The lines represent a best fit through the mean of the dependent variable in bins of 200 points each. A roughly linear inverse relationship is seen between the soil wetness and $\Omega_{E}(\mathrm{~S})-\Omega_{E}(\mathrm{~W})$. The scatterplot shows that the total evaporation (ET) is more sensitive to land state in dry climates than in areas with moderate soil wetness. The results are consistent with the findings of Dirmeyer et al. (2000), who showed that the sensitivity of surface fluxes to variations in soil moisture is generally concentrated at the dry end of the range of the soil moisture index. In contrast, the standard deviation of ET $\left(\sigma_{E}\right)$ is not large for low soil moisture, simply because ET itself is small in such regions. Put together, the product $\left[\Omega_{E}(\mathrm{~S})-\Omega_{E}(\mathrm{~W})\right] \sigma_{E}(\mathrm{~W})$ has minima for very wet and very dry soils, and it is largest for intermediate soil moisture values (with a degree of saturation between 0.1 and 0.4 ; see Fig. 3c). Figure $3 d$ shows, for comparison, how $\Omega_{P}(\mathrm{~S})-\Omega_{P}(\mathrm{~W})$ varies with soil moisture; the relationship shows a hint of that seen for $\left[\Omega_{E}(\mathrm{~S})-\Omega_{E}(\mathrm{~W})\right] \sigma_{E}(\mathrm{~W})$, particularly at the extremes.

The conclusions above were obtained from a multimodel average. We now examine, with some simple 

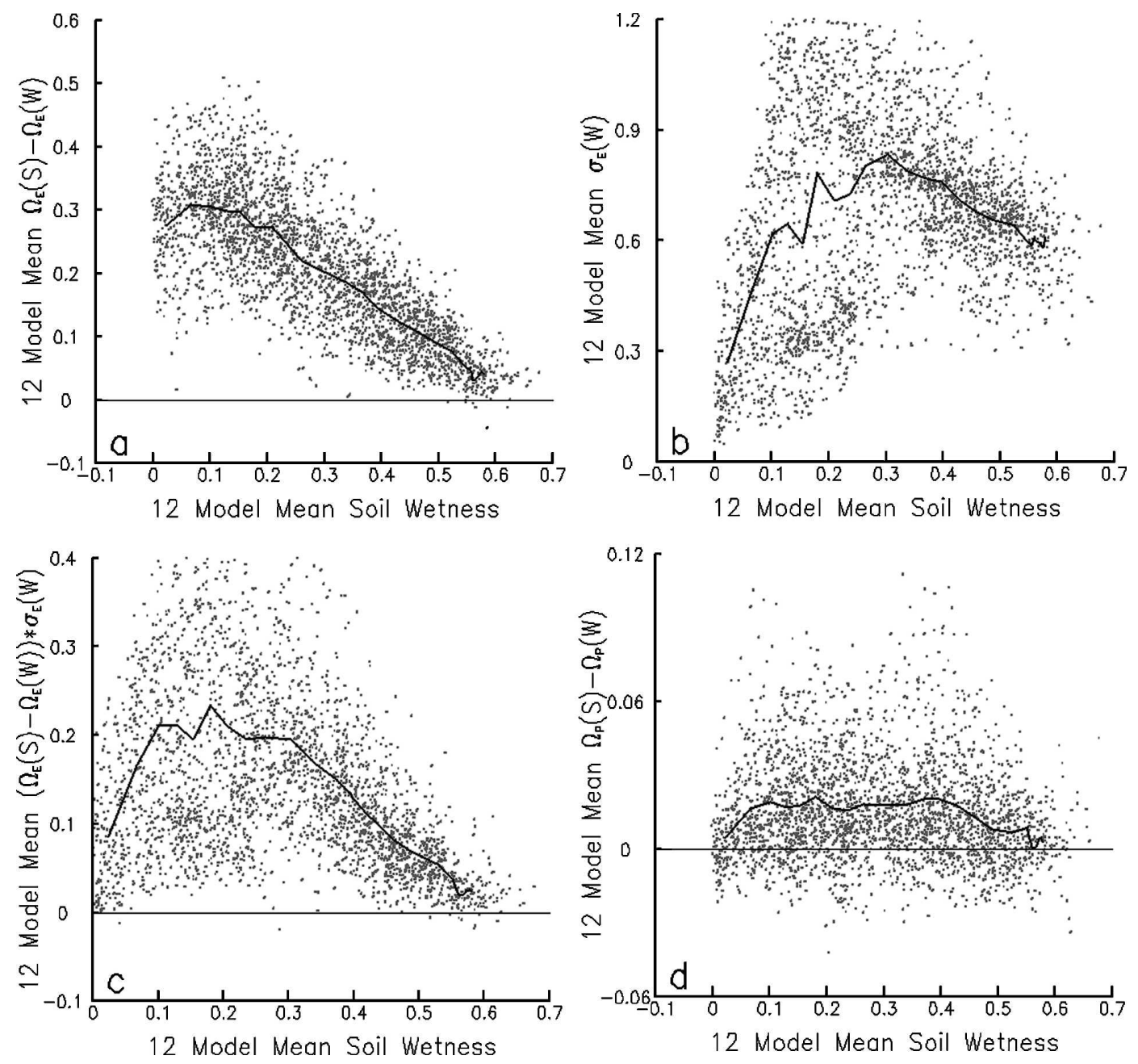

Fig. 3. Scatterplots of (a) $\Omega_{E}(\mathrm{~S})-\Omega_{E}(\mathrm{~W})$, (b) $\sigma_{E}$, (c) $\left[\Omega_{E}(\mathrm{~S})-\Omega_{E}(\mathrm{~W})\right] \sigma_{E}$, and (d) $\Omega_{P}(\mathrm{~S})-\Omega_{P}(\mathrm{~W})$, all against mean soil wetness. All variables are averaged across the 12 models.

statistical indicators, their relevance to individual models. First, consider the panels on the left in Fig. 4. The top panels show the intermodel standard deviation of $\Omega(\mathrm{S})-\Omega(\mathrm{W})$ among the 12 models, and the bottom panels show the ratio of the mean to the standard deviation. The pattern of the intermodel standard deviation of $\Omega_{E}(\mathrm{~S})-\Omega_{E}(\mathrm{~W})$ (left) largely resembles the field of $\Omega_{E}(\mathrm{~S})-\Omega_{E}(\mathrm{~W})$ itself (Fig. 1), except for the enhanced variability over arid regions. The ratio serves as a measure of the signal-to-noise ratio, showing where there is the least uncertainty among models. The pattern of the ratio resembles that of the mean in the upper-right panel in Fig. 1, with some shift away from the arid regions, giving a distribution that overlaps many of the world's major agricultural areas.

The implication of the left panels in Fig. 4 is that the regions of strong ET similarity are relatively common among the models. The same cannot be said about pre- cipitation similarity $\left[\Omega_{P}(\mathrm{~S})-\Omega_{P}(\mathrm{~W})\right]$. The right panels in Fig. 4 show the standard deviation and signal-tonoise ratio for precipitation similarity. The ratio of the mean to the standard deviation for precipitation similarity is much weaker than for ET, and is more dominated by noise. Only over a few regions (e.g., northern India, China, Pakistan, and parts of sub-Saharan Africa) are there sizeable areas that approach a ratio of unity (note the difference in scale). Note also that the strongest signal-to-noise values are still located in regions with strong levels of 12-model mean precipitation similarity in the upper-left panel of Fig. 1. Large, intermodel variability, however, predominates over most of the globe.

\section{Comparison among AGCMs}

While the models show some similarities in the geographical pattern of land-atmosphere coupling strength, 

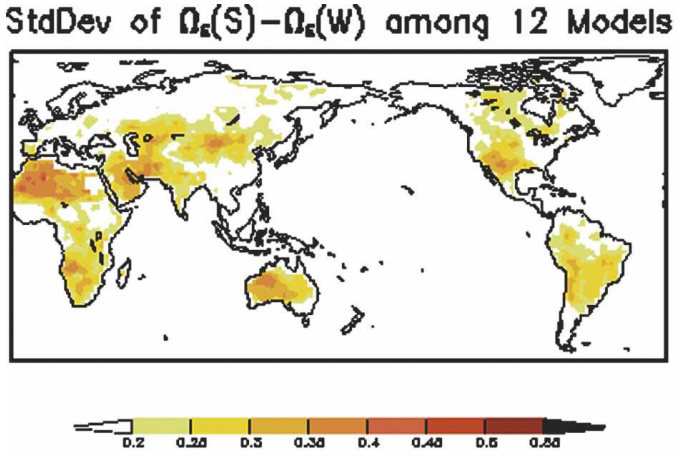

Mean / StdDev for $\Omega_{\mathrm{E}}(S)-\Omega_{\mathrm{E}}(W)$
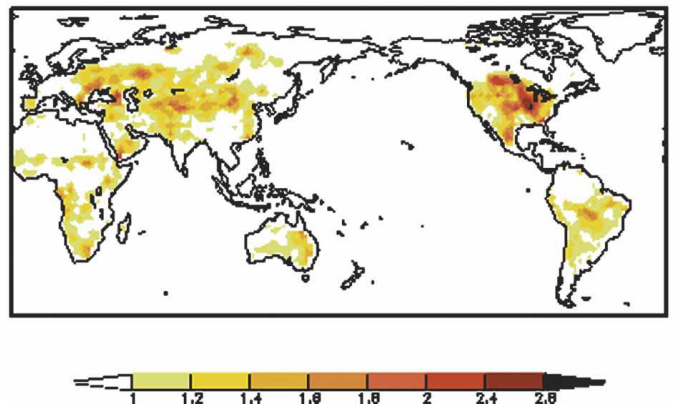

StdDev of $\Omega_{p}(S)-\bigcap_{p}(W)$ omong 12 Models
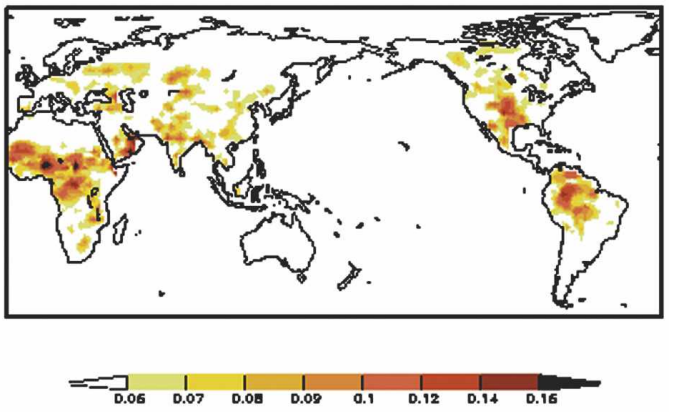

Mean / StdDev for $\Omega_{\mathrm{p}}(S)-\Omega_{\mathrm{p}}(W)$
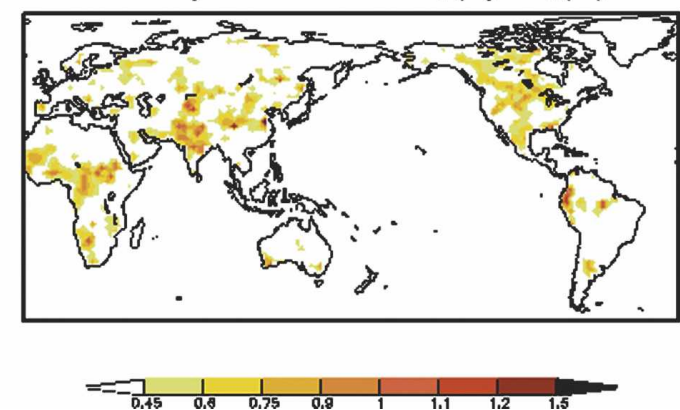

FIG. 4. Intermodel std $\operatorname{dev}$ of $\Omega_{E}(\mathrm{~S})-\Omega_{E}(\mathrm{~W})$ and $\Omega_{P}(\mathrm{~S})-\Omega_{P}(\mathrm{~W})$ among (top) the 12 models and (bottom) the ratio of the mean to the std dev.

they also show some wide disparities. Global maps of $\Omega_{P}(\mathrm{~S})-\Omega_{\mathrm{P}}(\mathrm{W})$ were provided in Fig. 5 of Part I for all 12 AGCMs. The major features found in the multimodel mean are seen in many of the models. Some areas, though, such as the northern Amazon and Orinoco Basins, show significant differences. Also, the coupling strength in general seems relatively large in the Geophysical Fluid Dynamics Laboratory (GFDL), National Aeronautics and Space Administration (NASA) Seasonal-to-Interannual Prediction Project (NSIPP), and Community Atmospheric Model, version 3 (CAM3), models, whereas that for the Global Forecast System Model (GFS)/Oregon State University land surface model (OSU) seems very weak.

Similar commonalities and disparities among AGCMs can be found in the impacts of soil moisture on ET. We showed in section 2 that the diagnostic $\left[\Omega_{E}(\mathrm{~S})-\right.$ $\left.\Omega_{E}(\mathrm{~W})\right] \sigma_{E}(\mathrm{~W})$, which measures the degree to which the evaporation signal is both similar and strong, appears to explain much of the geographical variation in the precipitation similarity for the mean of the models. Figure 5 shows global maps of this product for each model. The models tend to agree in the placement of larger values in the transition regions between humid and dry climates, but disparities abound. The GFDL model has the highest mean values for the product, whereas GFS/OSU has by far the lowest. Indeed, the low values for GFS/OSU by themselves can explain this model's globbally low precipitation similarity values.

Differences in this diagnostic product are indeed related to differences in the land-atmosphere coupling strength. Figure 6 shows how $\left[\Omega_{E}(\mathrm{~S})-\Omega_{E}(\mathrm{~W})\right] \sigma_{E}(\mathrm{~W})$ varies with $\Omega_{P}(\mathrm{~S})-\Omega_{P}(\mathrm{~W})$ for the average of global ice-free land points and for the three hot spot regions delineated by dashed lines in Fig. 1. The high $r^{2}$ values for the hot spot regions $(0.86,0.84$, and 0.51 over the Sahel, northern India, and the central Great Plains of North America, respectively) suggest that the intermodel differences in $\left[\Omega_{E}(\mathrm{~S})-\Omega_{E}(\mathrm{~W})\right] \sigma_{E}(\mathrm{~W})$ are strongly related, and, given the arguments in section 2 , largely explain the intermodel differences in $\Omega_{P}(\mathrm{~S})-$ $\Omega_{P}(\mathrm{~W})$ in these regions. (Note that for the global mean in Fig. 6a, the $r^{2}$ value appears to be determined mostly by the position of one point.) Supplemental calculations show that $\Omega_{E}(\mathrm{~S})-\Omega_{E}(\mathrm{~W})$ alone would produce $r^{2}$ values of $0.84,0.56$, and 0.38 , respectively, in the hot spot regions, while $\sigma_{E}(\mathrm{~W})$ alone would produce $r^{2}$ values of $0.11,0.62$, and 0.40 , respectively.

Of course, the relationship is not perfect because of sampling error, the inability of the diagnostic to capture fully the evaporation signal's impact on land-atmosphere feedback, and the fact that the models also differ 
$\left(\Omega_{\varepsilon}(S)-\Omega_{\varepsilon}(W)\right) * \sigma_{\varepsilon}(W)$

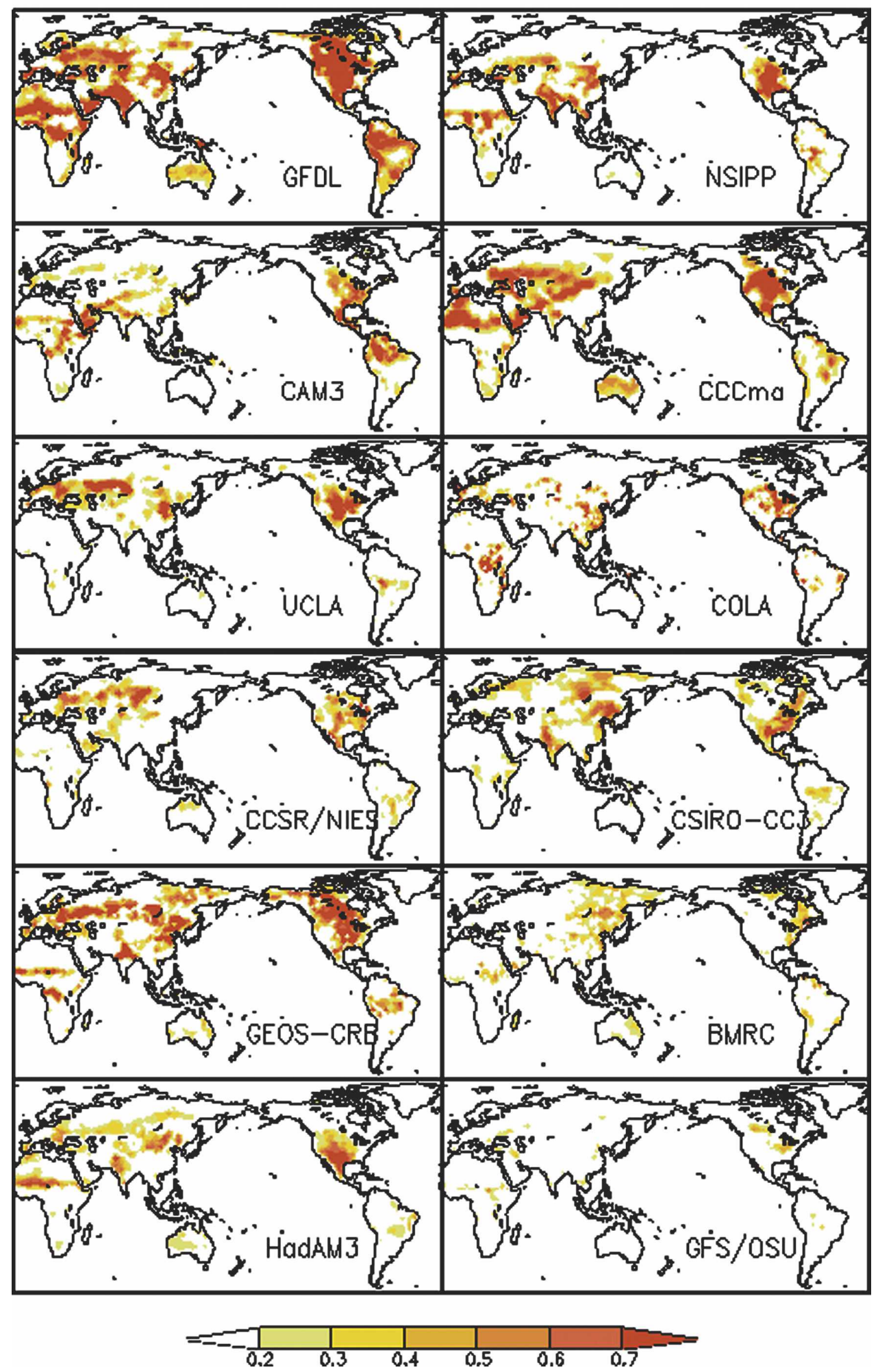

FIG. 5. Global distribution of $\left[\Omega_{E}(\mathrm{~S})-\Omega_{E}(\mathrm{~W})\right] \sigma_{E}$ for the models participating in GLACE. 

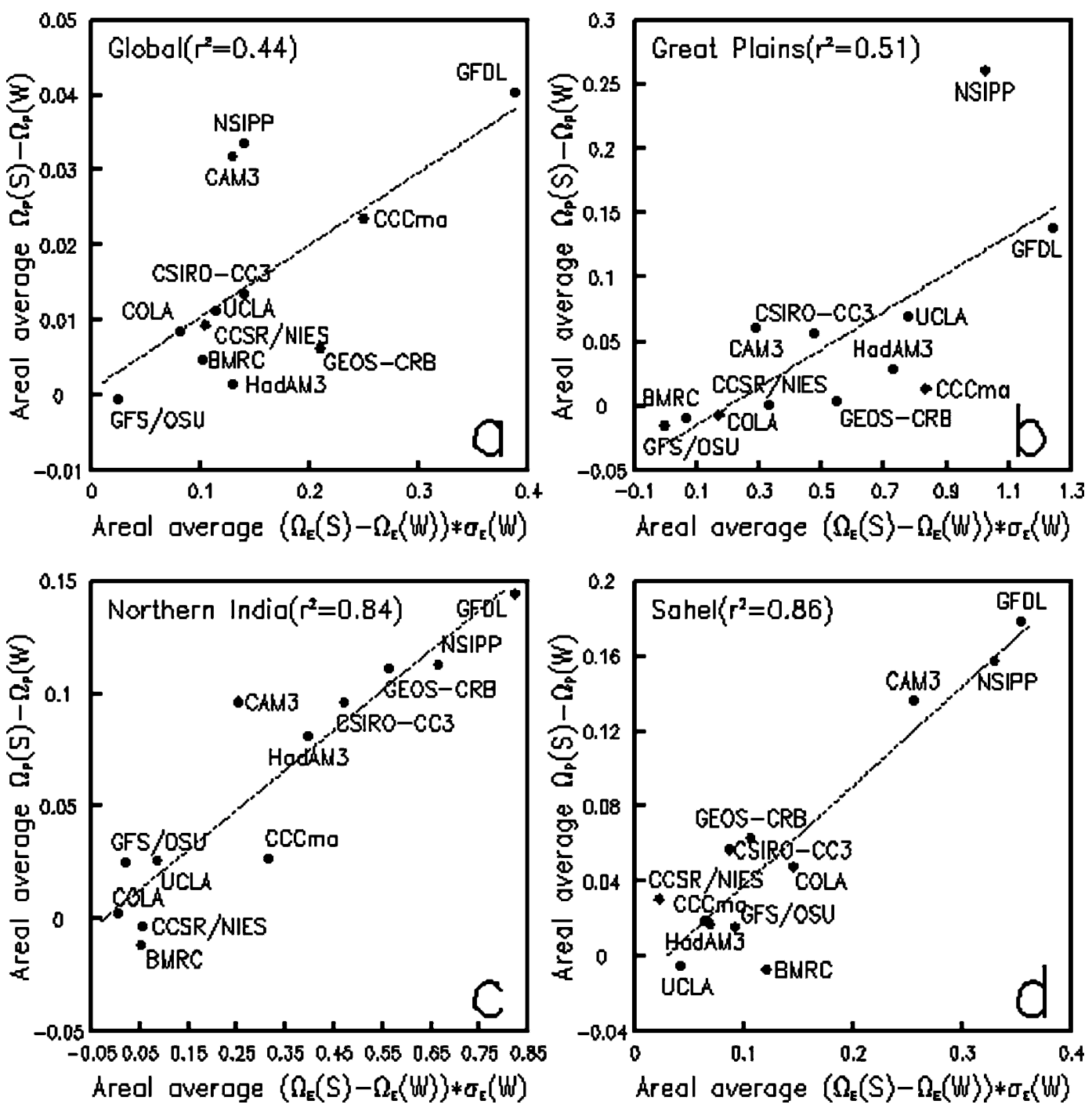

FIG. 6. Areal average of $\left[\Omega_{E}(\mathrm{~S})-\Omega_{E}(\mathrm{~W})\right] \cdot \sigma_{E}$ vs $\Omega_{P}(\mathrm{~S})-\Omega_{P}(\mathrm{~W})$ over global ice-free land points and some hot spot regions (indicated by dashed lines in Fig. 1) for all 12 models.

in the coupling mechanism between ET and precipitation (section $3 \mathrm{c}$ ). Indeed, the separation of the pathway linking soil moisture anomalies and precipitation generation into two parts - the segment between soil moisture anomalies and evaporation anomalies and that between evaporation anomalies and precipitation generation-is useful for understanding the intermodel differences in $\Omega_{P}(\mathrm{~S})-\Omega_{P}(\mathrm{~W})$. In essence, Fig. 6 suggests that while the first segment is the most important for explaining these differences [the $r^{2}$ values for between the associated diagnostic and $\Omega_{P}(\mathrm{~S})-\Omega_{P}(\mathrm{~W})$ are high], it is not all important.

In the remainder of this section, we focus more closely on the models' representations of these two segments. We construct a series of indices to measure the overall strength of each segment within each model, as well as the strength of coupling for the entire path from soil wetness to precipitation. The results are summarized in Table 1.

\section{a. Soil-precipitation coupling: Net effect}

The first column after the list of models in Table 1 shows the global mean of the precipitation similarity diagnostic $\Omega_{P}(\mathrm{~S})-\Omega_{P}(\mathrm{~W})$ calculated over all nonice land points. The next column provides the rank of the model (with 1 indicating the highest global mean, and thus the model with the strongest control of subsurface soil moisture on precipitation). Some grouping is evident; three models (GFDL, NSIPP, and CAM3) show similarly large values of the global mean index (between 0.032 and 0.040), and another group [Commonwealth Scientific and Industrial Research Organization 
TABLE 1. Globally averaged (over nonice land points) land-atmosphere coupling strength for all 12 models and in each segment of the path from soil wetness to precipitation, namely, soil wetness-ET and ET-precipitation. Subscripts "1" and "2" are used to identify the different methods for calculating the indices (see section $3 \mathrm{c}$ for details).

\begin{tabular}{|c|c|c|c|c|c|c|c|c|}
\hline Model & $\mathrm{SW}-P$ & Rank & $\mathrm{SW}-\mathrm{ET}$ & Rank & $(\mathrm{ET}-P)_{1}$ & Rank & $(\mathrm{ET}-P)_{2}$ & Rank \\
\hline GFDL & 0.040 & 1 & 0.387 & 1 & 0.211 & 7 & 0.104 & 4 \\
\hline NSIPP & 0.034 & 2 & 0.140 & 5 & 0.511 & 2 & 0.241 & 2 \\
\hline CAM3 & 0.032 & 3 & 0.129 & 7 & 0.715 & 1 & 0.248 & 1 \\
\hline $\mathrm{CCCma}$ & 0.024 & 4 & 0.249 & 2 & 0.450 & 4 & 0.095 & 7 \\
\hline CSIRO & 0.014 & 5 & 0.151 & 4 & 0.042 & 11 & 0.097 & 6 \\
\hline UCLA & 0.011 & 6 & 0.114 & 8 & 0.267 & 6 & 0.099 & 5 \\
\hline CCSR & 0.009 & 7 & 0.104 & 9 & 0.453 & 3 & 0.090 & 8 \\
\hline COLA & 0.009 & 8 & 0.081 & 11 & 0.370 & 5 & 0.106 & 3 \\
\hline GEOS & 0.006 & 9 & 0.209 & 3 & 0.162 & 9 & 0.030 & 10 \\
\hline BMRC & 0.005 & 10 & 0.102 & 10 & 0.182 & 8 & 0.047 & 9 \\
\hline HadAM3 & 0.002 & 11 & 0.129 & 6 & -0.016 & 12 & 0.012 & 11 \\
\hline GFS & -0.004 & 12 & 0.024 & 12 & 0.082 & 10 & -0.017 & 12 \\
\hline
\end{tabular}

(CSIRO), University of California, Los Angeles (UCLA), Center for Climate System Research (CCSR), Center for Ocean-Land-Atmosphere Studies (COLA), Goddard Earth Observing System (GEOS), and Bureau of Meteorology Research Center (BMRC)] shows much lower values, ranging from 0.005 to 0.014 . The Hadley Centre Atmospheric Model (HadAM) 3 and GFS/OSU models show almost no impact of subsurface soil wetness on precipitation.

A comparison of the $\mathrm{R}$ and $\mathrm{S}$ experiments reveals how the specification of "faster" land variables (temperatures, etc.) affects the model rankings. In Fig. 7, global means of $\Omega_{P}(\mathrm{~S})-\Omega_{P}(\mathrm{~W})$ are plotted against $\Omega_{P}(\mathrm{R})-\Omega_{P}(\mathrm{~W})$ for each model. Similar groupings are evident. Notice that the rankings are similar (i.e., the points cluster along a diagonal line with positive slope)

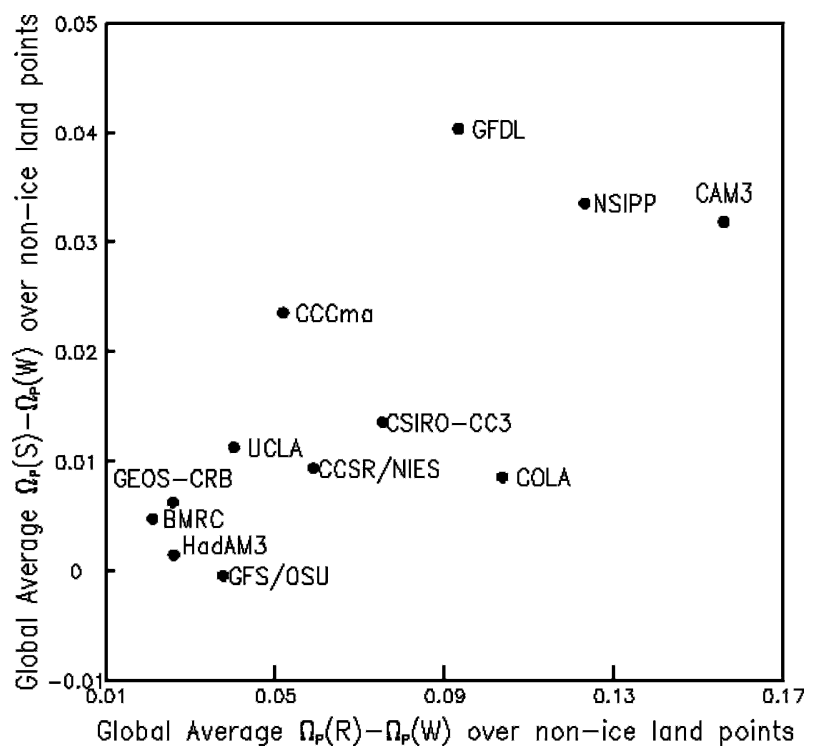

FIG. 7. Global average of $\Omega_{P}(\mathrm{~S})-\Omega_{P}(\mathrm{~W})$ vs $\Omega_{P}(\mathrm{R})-\Omega_{P}(\mathrm{~W})$ over ice-free land points for all 12 models. despite the differences in the scales of the axes. In general, if specifying subsurface soil moisture has a relatively large impact on the similarity of rainfall in a model, then the specification of all land variables in the model will also have a relatively large impact on precipitation.

\section{b. Segment 1: Soil-ET coupling}

The first segment of the path in soil-precipitation coupling is from soil wetness variations to ET variations, which we characterize with the diagnostic $\left[\Omega_{E}(\mathrm{~S})-\right.$ $\left.\Omega_{E}(\mathrm{~W})\right] \sigma_{E}(\mathrm{~W})$. Columns 4 and 5 in Table 1 show, respectively, the global mean of this diagnostic for each model (calculated over all nonice land points) and the model's corresponding rank. The GFDL model clearly has the strongest link between subsurface soil wetness and ET. There is a significant gap to the model in second place [Canadian Centre for Climate Modelling and Analysis (CCCma)], and then a fairly continuous spectrum down to the 11th model (COLA). GFS/OSU has a very weak coupling between soil wetness and ET and is a clear outlier. Note that the centers of the topmost soil layers of the GFDL, BMRC, CCCma, and HadAM3 models are at or are deeper than $5 \mathrm{~cm}$, meaning that for each of these four models, the soil moisture was continually specified in the topmost layer in the $\mathrm{S}$ experiment. Thus, for these four models only, bare soil evaporation was directly affected by the soil moisture specification in case $\mathrm{S}$, helping to increase $\Omega_{E}(\mathrm{~S})-$ $\Omega_{E}(\mathrm{~W})$. \{In the GFS/OSU model, the topmost soil layer was not continually specified in the $\mathrm{S}$ ensemble even though the center is exactly $5 \mathrm{~cm}$ from the surface. Although this implementation of the experiment is not precisely correct, it should have a limited impact on the computed global average of the $\left[\Omega_{E}(\mathrm{~S})-\right.$ $\left.\Omega_{E}(\mathrm{~W})\right] \sigma_{E}(\mathrm{~W})$ field. The whole of the root zone en- 

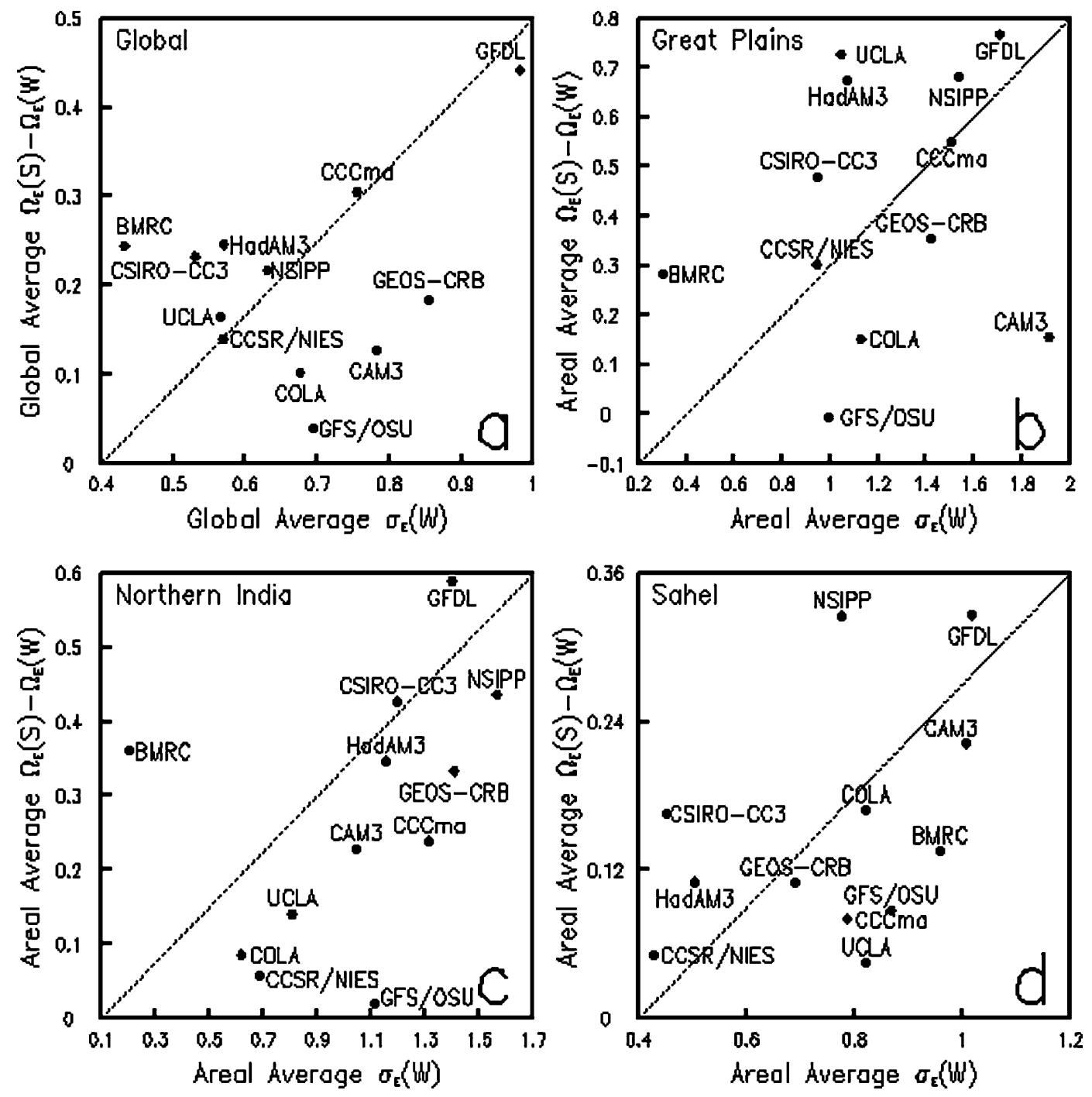

FIG. 8. $\Omega_{E}(\mathrm{~S})-\Omega_{E}(\mathrm{~W})$ vs $\sigma_{E}$ for all 12 models, averaged over (a) global ice-free land points, (b) the Great Plains,

(c) northern India, and (d) the Sahel. The boundaries of the final three regions are demarcated in Fig. 1.

compasses a much larger soil volume than the surface layer, and supplemental analysis of GFS/OSU's evaporation fields shows that although bare soil evaporation is dominant in some regions, transpiration dominates on the global scale.\}

As discussed in section 2, the diagnostic $\left[\Omega_{E}(\mathrm{~S})-\right.$ $\left.\Omega_{E}(\mathrm{~W})\right] \sigma_{E}(\mathrm{~W})$ captures two separate aspects of the evaporation signal: its variability and its similarity. Figure 8 shows, for each of the regions analyzed in Fig. 6, the individual quantities $\sigma_{E}$ and $\Omega_{E}(\mathrm{~S})-\Omega_{E}(\mathrm{~W})$ for each model. This breakdown helps us relate differences in the soil-ET coupling to differences in climate regime and model parameterization. Differences in $\sigma_{E}$ relate mostly to differences in the models' background climatologies (though $\sigma_{E}$ may potentially be amplified through its coevolution with $\sigma_{P}$ during feedback). Dif- ferences in $\Omega_{E}(\mathrm{~S})-\Omega_{E}(\mathrm{~W})$, on the other hand, relate mostly to differences in incident radiative energy and in the details of the land surface parameterization, particularly in those details defining the sensitivity of evaporation to soil moisture variations. For example, notice that in Figs. 8a-8c BMRC tends to have moderately high similarity in its evaporation fluxes $\left[\Omega_{E}(\mathrm{~S})-\right.$ $\Omega_{E}(\mathrm{~W})$ ], but very low variability $\left(\sigma_{E}\right)$ - the type of behavior idealized in the third panel of Fig. 2. The low $\sigma_{\mathrm{E}}$ for BMRC reflects the relatively low mean and variability of the precipitation forcing (not shown) for that model over most of the areas examined, that is, it results from the model's background climatology. The same arguments regarding evaporation variability apply, to a degree, to the CCSR/National Institute for Environmental Studies (NIES) model, particularly over 
northern India and the Sahel. The GFDL model, on the other hand, shows relatively high precipitation variability on a global scale, helping to promote evaporation variability. Coupled with the moderate-to-high $\Omega_{E}(\mathrm{~S})$ $-\Omega_{E}(\mathrm{~W})$ values for this model, the diagnostic $\left[\Omega_{E}(\mathrm{~S})\right.$ $\left.-\Omega_{E}(\mathrm{~W})\right] \sigma_{E}(\mathrm{~W})$ is especially high, promoting strong land-atmosphere feedback.

Now consider the COLA model. Evaporation (and precipitation) variability in the areas studied is not particularly small for this model, but the evaporation similarity values are (case ii in Fig. 2). These low similarity values probably reflect this model's relatively high interensemble variability of net radiation (not shown).

Again, details of the land model parameterization, particularly those associated with soil water-limited transpiration and how it relates in magnitude to bare soil evaporation and canopy interception loss, probably explain most of the intermodel differences in $\Omega_{E}(\mathrm{~S})-$ $\Omega_{E}(\mathrm{~W})$. The parameterization in the GFS/OSU model, for example, must be responsible for this model's very low $\Omega_{\mathrm{E}}(\mathrm{S})-\Omega_{\mathrm{E}}(\mathrm{W})$. In the India region, at least, the GFS/OSU model does produce a bare soil evaporation that exceeds transpiration (not shown). [Curiously, another land model used at the National Centers for Environmental Prediction (NCEP), the Noah LSM, shows substantial evaporation sensitivity to soil moisture variations when coupled to NCEP's Eta regional model (Berbery et al. 2003).] A proper analysis of such model parameterization differences would necessarily be complex and will not be addressed in this paper.

Other climatic factors may also lead to intermodel differences in $\left[\Omega_{E}(\mathrm{~S})-\Omega_{E}(\mathrm{~W})\right] \sigma_{E}(\mathrm{~W})$. For example, because this diagnostic peaks at intermediate values of soil wetness (Fig. 3), the model whose climatology produces the highest fractional area with such soil wetness values might produce the highest average value for the diagnostic. Also, if a model shows large similarity in evaporation rates in the free-running $W$ experiment $\left[\Omega_{E}(\mathrm{~W})\right]$ resulting from the initialization procedure or the effects of the oceanic boundary conditions and seasonal radiation forcing applied, the difference $\Omega_{E}(S)-$ $\Omega_{E}(\mathrm{~W})$ may have a small upper potential limit. Careful analysis of the model output, however, shows that neither factor has a first-order impact on the ranking of the models.

Finally, a comparison of the evaporation diagnostics computed from the $\mathrm{R}$ and $\mathrm{S}$ experiments provides some interesting insights into the control of evaporation in the different models. Figure 9a shows the global mean (over nonice land points) of $\left[\Omega_{E}(\mathrm{~S})-\Omega_{E}(\mathrm{~W})\right] \sigma_{E}(\mathrm{~W})$ versus the corresponding global mean of $\left[\Omega_{E}(\mathrm{R})-\right.$ $\left.\Omega_{E}(\mathrm{~W})\right] \sigma_{E}(\mathrm{~W})$. Because more variables (i.e., the fast variables, including surface soil moisture, skin temp- erature, and canopy interception) are specified in the $\mathrm{R}$ than in the $\mathrm{S}$ experiment, we expect the evaporation similarity to be larger for the $\mathrm{R}$ experiment, and thus we expect $\left[\Omega_{E}(\mathrm{R})-\Omega_{E}(\mathrm{~W})\right] \sigma_{E}(\mathrm{~W})$ to be larger than $\left[\Omega_{E}(\mathrm{~S})-\Omega_{E}(\mathrm{~W})\right] \sigma_{E}(\mathrm{~W})$. This is seen in general on the global scale. Some models (CAM3, GFS/ OSU, and COLA) show a relatively large difference between $\left[\Omega_{E}(\mathrm{R})-\Omega_{E}(\mathrm{~W})\right] \sigma_{E}(\mathrm{~W})$ and $\left[\Omega_{E}(\mathrm{~S})-\right.$ $\left.\Omega_{E}(\mathrm{~W})\right] \sigma_{E}(\mathrm{~W})$, suggesting that evaporation in these models is more strongly controlled by the fast variables. The higher values of the diagnostic for the $\mathrm{R}$ experiment have consequent impacts on the land-atmosphere coupling strength in that experiment, $\Omega_{P}(\mathrm{R})-\Omega_{P}(\mathrm{~W})$ (Fig. 7).

Similar behavior is observed over the Great Plains and the Sahel (Figs. 9b,d). Interestingly, the specification of the fast variables over India (Fig. 9c) has an impact on only a handful of models (COLA, UCLA, GFS/OSU, CAM3, and CCCma); the rest of the models fall close to the 1:1 line.

\section{c. Segment 2: ET-precipitation coupling}

The land surface model and the background climatology may combine to produce a strong and similar evaporation signal, as in the lowest panel of Fig. 2. For this to be translated into an impact on precipitation, however, the second segment of land-atmosphere feedback-the link between evaporation and precipitation-must be strong. Returning to Table 1, we present two different indices to measure this link. Both indices are inferred from joint analysis of diagnosed precipitation and ET similarities.

The first index $(\mathrm{ET}-P)_{1}$ is simply the spatial pattern correlation between $\left[\Omega_{E}(\mathrm{R})-\Omega_{E}(\mathrm{~W})\right] \sigma_{E}(\mathrm{~W})$ and $\Omega_{P}(\mathrm{R})-\Omega_{P}(\mathrm{~W})$ across the globe. The idea is simple: if the control of ET on precipitation is local and strong, then the spatial patterns of the evaporation diagnostic and the precipitation similarity should be highly correlated. The correlations from the $\mathrm{R}$ experiment are similar to those from the $\mathrm{S}$ experiment; we use those from the $\mathrm{R}$ experiment here simply because they will not be spuriously high because of the response of bare soil evaporation or interception loss to incident precipitation.

The second index $(\mathrm{ET}-P)_{2}$ is the ratio between the global means (over nonice land points) of $\Omega_{P}(\mathrm{~S})-$ $\Omega_{P}(\mathrm{~W})$ and $\left[\Omega_{E}(\mathrm{~S})-\Omega_{E}(\mathrm{~W})\right] \sigma_{E}(\mathrm{~W})$. This gives a global measure of how the second segment of landatmosphere coupling (i.e., between evaporation and precipitation) degrades the link between soil moisture and precipitation, without regard for the "localness" or "remoteness" of the evaporation impacts.

Table 1 shows that the two indices produce similar 

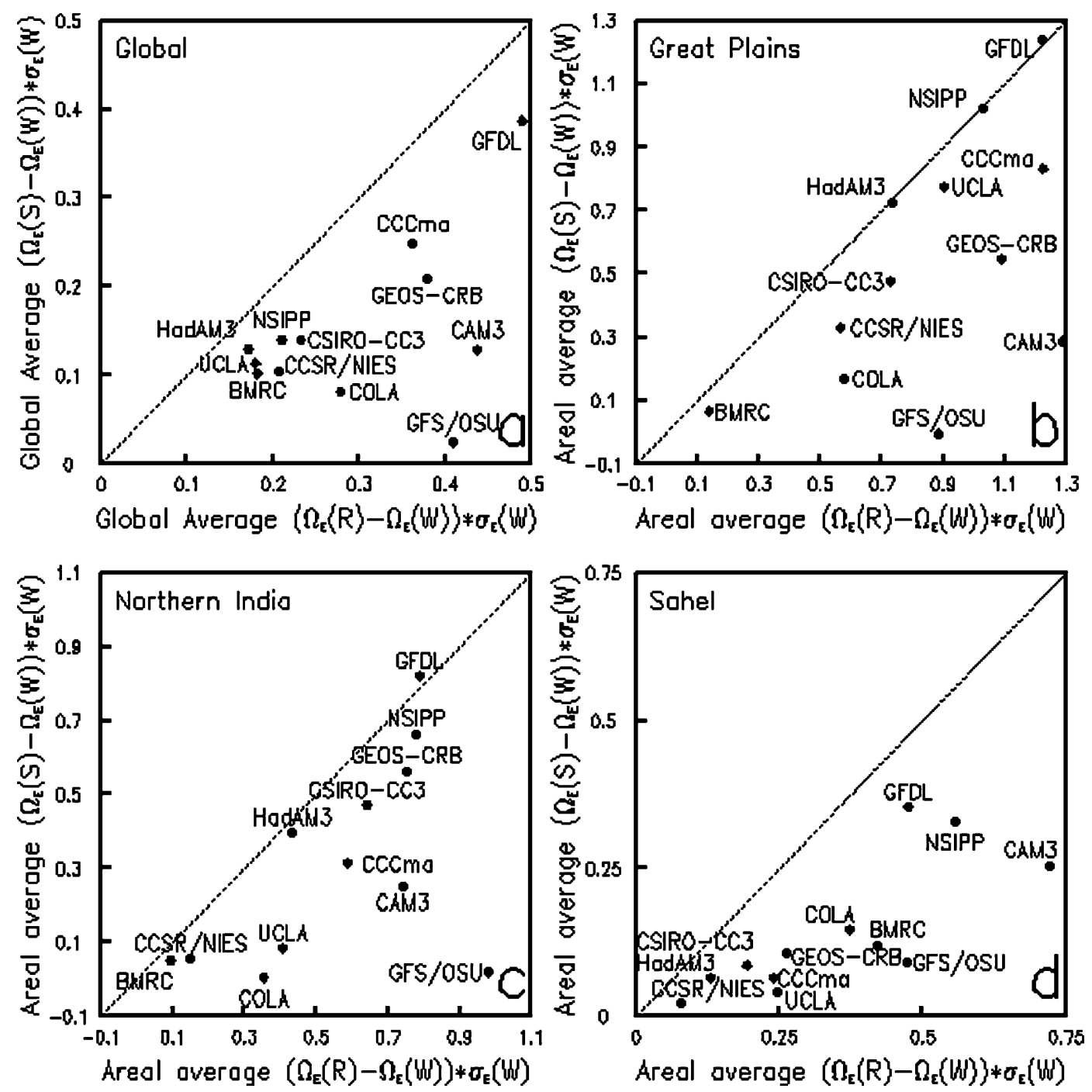

FIG. 9. $\left[\Omega_{E}(\mathrm{~S})-\Omega_{E}(\mathrm{~W})\right] \sigma_{E}$ vs $\left[\Omega_{E}(\mathrm{R})-\Omega_{E}(\mathrm{~W})\right] \sigma_{E}$ for all 12 models, averaged over (a) global ice-free land points, (b) the Great Plains, (c) northern India, and (d) the Sahel. The boundaries of the final three regions are demarcated in Fig. 1.

rankings among the models. The CAM3 and NSIPP models rank considerably higher than the other models in both indices, suggesting that their parameterizations for moist convection, boundary layer physics, and/or other atmospheric processes are especially sensitive to evaporation variations at the land surface. GEOS and HadAM3 show much lower rankings for the ET- $P$ index than for the SW-ET index, suggesting that the ET $-P$ connection is weak enough to lose whatever signal is transmitted from soil wetness to ET. Both CAM3 and COLA show strong values of the ET $-P$ indices but do not rank high in the SW-ET index, suggesting that these models might have an even stronger coupling between soil wetness and precipitation if a different land surface parameterization were used or (in the case of the COLA model) if the net radiation were less variable. Finally, the small values of all indices for GFS/ OSU and BMRC suggest that the lack of signal in ET may prevent any measure of ET- $P$ coupling; again, a change of land surface scheme might dramatically alter the behavior of these two models.

The ratio-based index $(\mathrm{ET}-P)_{2}$ can be used to interpret the scatter in Fig. 6a, which is the plot showing the relationship between globally averaged numerator $\Omega_{P}(\mathrm{~S})-\Omega_{P}(\mathrm{~W})$ and denominator $\left[\Omega_{E}(\mathrm{~S})-\right.$ $\left.\Omega_{E}(\mathrm{~W})\right] \sigma_{E}(\mathrm{~W})$ for the different models. The CAM3 and NSIPP models lie well above a fitted line through the points. The interpretation of the ratio-based index $(\text { ET }-P)_{2}$ explains why these two models have atmospheres that are (relatively) sensitive to evaporation 


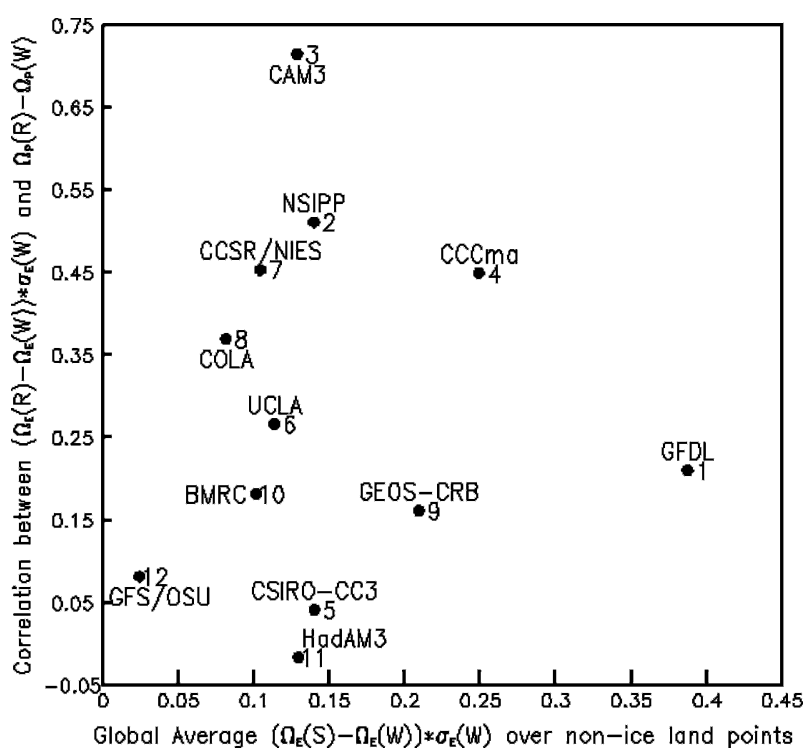

FIG. 10. Global average of $\left[\Omega_{E}(\mathrm{~S})-\Omega_{E}(\mathrm{~W})\right] \sigma_{E}$ over ice-free land points (a measure of the strength of the soil moistureevaporation connection) vs spatial pattern correlation between $\left[\Omega_{E}(\mathrm{R})-\Omega_{E}(\mathrm{~W})\right] \sigma_{E}$ and $\Omega_{P}(\mathrm{R})-\Omega_{\mathrm{P}}(\mathrm{W})$ (a measure of the strength of the evaporation-precipitation connection) for all 12 models.

variations. Similarly, the fact that GEOS and HadAM3 lie below the fitted line can be explained by the relative insensitivity of their atmospheres to evaporation variations.

Figure 10 summarizes the results of separating landatmosphere feedback into the two segments. The $x$ axis represents the first segment of the coupling-the link between soil wetness and ET. The $y$ axis represents the second segment - the link between ET and precipitation as provided by the correlation-based diagnostic $(\text { ET }-P)_{1}$. The number near each model name in Fig. 10 shows how the model ranks in total coupling strength over all ice-free land points (from column 3 of Table 1).

The coupling strength in a model, of course, is controlled by the nature of both segments of the coupling. The closer a model is to the upper-right corner of the plot, the more likely a soil wetness anomaly can propagate through the ascending branch of the hydrologic cycle and affect precipitation. The figure immediately highlights some of the results outlined above; for example, the low coupling strengths of the BMRC and COLA models results from their weak soil moistureevaporation connection, whereas the high coupling strength for the GFDL model results from its very strong soil moisture-evaporation connection. Coupling strength is strong in models such as NSIPP and CAM3 mostly because of the strong connection between ET and precipitation in these two models. The HadAM3, on the other hand, shows the weakest coupling between ET and precipitation, and it thus has one of the weakest coupling strengths. The HadAM3 result is consistent with findings from a recent study (Lawrence and Slingo $2004 a, b)$ that showed how the inclusion of predicted vegetation phenology in this model had no impact on precipitation, even though soil wetness, surface latent heat flux, and near-surface air temperature were all significantly affected over large areas of the globe. The GFS/OSU model lies near the origin and has the weakest coupling strength because both the soil moistureevaporation connection and coupling between ET and precipitation are weak.

\section{d. Link between coupling strength and convection}

Coupling strength is a net result of complex interactions between numerous process parameterizations in the AGCM. We have discerned different behaviors of land-atmosphere coupling among the 12 AGCMs in this study and have broken down the contributions to this coupling from the atmospheric and terrestrial branches of the hydrologic cycle. Can we identify the process parameterizations that are mostly responsible for the differing coupling strengths?

We now examine moist convective precipitation with this in mind. Given that moist convection is often instigated by variations in near-surface air temperature and humidity, whereas large-scale condensation is strongly controlled by variations in the general circulation, we might naturally expect moist convection to be a key component of the pathway linking soil moisture variations and precipitation. Figure 11a shows the global average of $\Omega_{P}(\mathrm{~S})-\Omega_{P}(\mathrm{~W})$ calculated separately for total precipitation, convective precipitation, and largescale precipitation. (Note that only seven models reported the precipitation components separately.) With the exception of the NSIPP model, the contribution of soil moisture to similarity in the convective component is $60 \%-200 \%$ greater than its contribution to similarity in the large-scale component. The fact that $\Omega_{P}(\mathrm{~S})-$ $\Omega_{P}(\mathrm{~W})$ tends to be larger for convective precipitation than for large-scale precipitation supports the idea that convective precipitation is more sensitive to land surface moisture variations.

In Fig. $11 \mathrm{~b}$, the $\Omega_{P}(\mathrm{~S})-\Omega_{P}(\mathrm{~W})$ values are weighted by the fractional contributions of the convective precipitation component to total precipitation. This plot shows that convective precipitation bears most of the signal of the soil moisture's impact on precipitation, due in large part to the dominance of convective precipitation during boreal summer. Based on the bottom plot, the coupling between surface fluxes and precipi- 

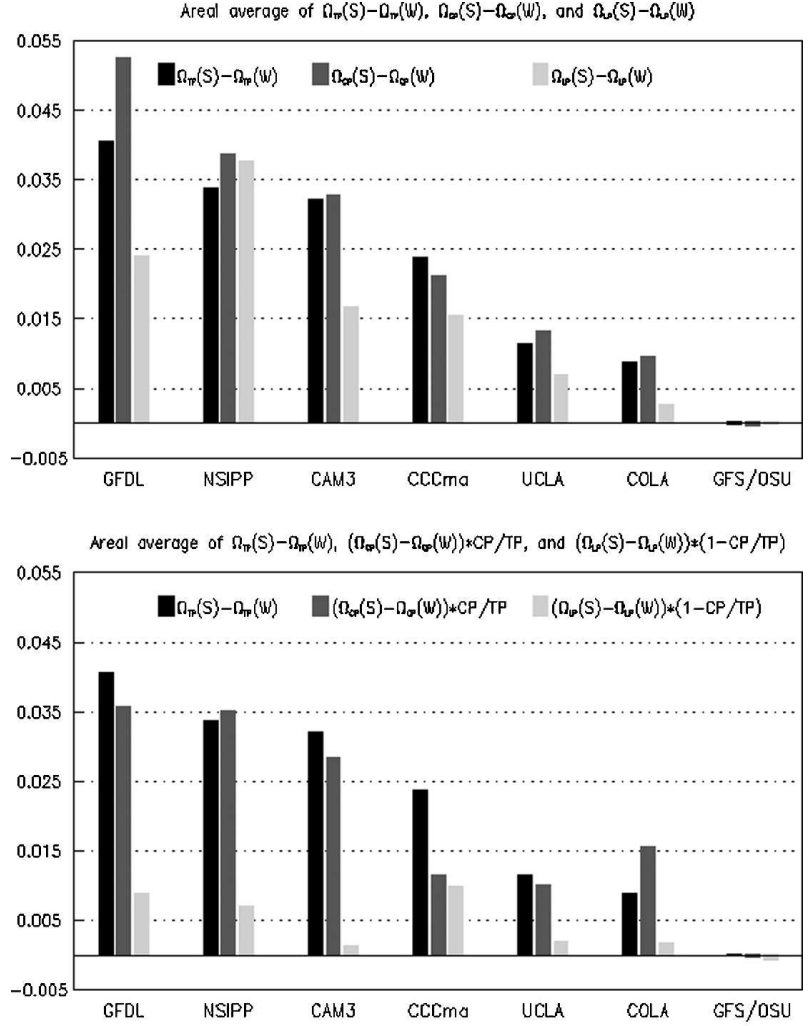

FIG. 11. (top) Global average over ice-free land points of $\Omega_{P}(\mathrm{~S})$ - $\Omega_{P}(\mathrm{~W})$ calculated separately from total precipitation, convective, and large-scale precipitation components for the models that reported them separately. (bottom) Same as above, but with values scaled by the relative contributions of the components to total precipitation.

tation is indeed via the convective precipitation scheme in the AGCMs.

Not examined separately here are the many aspects of the moist convective parameterization (convective triggers, depth of detrainment, droplet microphysics, evaporation of falling rain, downdrafts) that can affect the evolution of temperature and humidity of the boundary layer and can thus induce intermodel differences in simulated land-atmosphere coupling strength. Additional sensitivity experiments with more comprehensive diagnostics, perhaps in a single-column model setting, would be needed to address more fully the role of moist convection in the coupling.

\section{Discussion and summary}

Through coordinated numerical experiments with 12 AGCMs as part of the GLACE project, the impacts of soil moisture conditions on rainfall generation have been examined for the boreal summer season. These impacts are found to be a function of hydroclimatological regime and are heavily affected by the complex physical process parameterizations implemented in the AGCM.

In general, impacts of soil moisture on rainfall are strong only in the transition zones between dry and wet areas. Multimodel analysis shows that the existence of "hot spots" of land-atmosphere coupling in these areas is because of the coexistence there of a high sensitivity of ET to soil moisture and a high temporal variability of the ET signal. In wet climates, where soil moisture is plentiful, ET is controlled not by soil moisture but also by atmospheric demand (as determined in part by net radiation). Specifying land moisture states in wet climates thus has little impact on ET and rainfall generation (cases $i$ and ii in Fig. 2). In dry climates, ET rates are sensitive to soil moisture, but the typical variations are generally too small to affect rainfall generation (case iii in Fig. 2). Only in the transition zone between wet and dry climates, where ET variations are suitably high but are still sensitive to soil moisture, do the land states tend to have strong impacts on precipitation.

The impact of soil moisture on rainfall varies widely from model to model. The GFDL, CAM3, and NSIPP models have the strongest land-atmosphere coupling strengths, and GFS/OSU, HadAM3, BMRC, and GEOS have the weakest (Table 1). The breakdown of the coupling mechanism into two segments-the link between soil moisture and evaporation and the link between evaporation and precipitation-helps to identify some of the reasons for these differences. Some models (CAM3, NSIPP) have a high coupling strength because their modeled atmospheres (particularly their convective schemes) are very sensitive to evaporation variations, whereas the atmospheres of other models (HadAM3, GEOS) are relatively insensitive to evaporation variations, leading to a weak coupling strength. Most of the intermodel differences in coupling strength, however, can be explained by intermodel differences in the nature of the evaporation signal itself, as characterized by the diagnostic product $\left[\Omega_{E}(\mathrm{~S})-\right.$ $\left.\Omega_{E}(\mathrm{~W})\right] \sigma_{E}(\mathrm{~W})$. Figure 6 suggests that in some of the hot spot regions of strong coupling, intermodel variations in the diagnostic product can explain more than $80 \%$ of the intermodel variations in coupling strength. Figures $8 \mathrm{a}$ and 10 summarize the impacts of the various factors on globally averaged coupling strength for each model.

In Part I, we noted that the $\Omega_{P}$ diagnostic does not distinguish between local and remote land surface influences on precipitation. One interpretation of the overall strong performance of the diagnostic product $\left[\Omega_{E}(\mathrm{~S})-\Omega_{E}(\mathrm{~W})\right] \sigma_{E}(\mathrm{~W})$ in reproducing $\Omega_{P}$ is that the 
coupling between precipitation and soil moisture is indeed largely local. Additional experiments would be needed to demonstrate this more definitively.

For the understanding of land-atmosphere coupling strength, we can identify several additional issues that require further attention. First, an objective quantification of large-scale coupling strength from observational data needs to be obtained; its absence is a major obstacle to the evaluation of model performance. Second, land-atmosphere coupling strength should be quantified for other seasons; presumably, it will be weaker during seasons that feature less moist convection, though preliminary experiments with the CCSR/NIES model (not shown) suggest otherwise. Third, for a more detailed analysis of coupling strength in a more controlled setting, different configurations of convective precipitation schemes, boundary layer schemes, and ET formulations should be applied within individual models. In particular, the use of implicit coupling of the land surface to the atmosphere (Polcher et al. 1998; Best et al. 2004), rather than the more common explicit or semi-implicit approaches, should be investigated, because the former may lead to a "tighter" connection between the land surface and the planetary boundary layer, with consequent impacts on derived coupling strength. Finally, the strength of land-atmosphere coupling should be quantified relative to that of other controls in the earth's climate system; for example, comparing the GLACE results above with those from a separate set of ensembles that use different SST boundary conditions for each ensemble member (drawn from observed interannual SST distributions) could establish the relative importance of land and ocean controls on precipitation variability.

Acknowledgments. We thank Robert Dickinson and two anonymous reviewers for their helpful comments. GLACE is a joint project of the Global Energy and Water Cycle Experiment (GEWEX) Global Land Atmosphere System Study (GLASS) and the Climate Variability Experiment (CLIVAR) Working Group on Seasonal-Interannual Prediction (WGSIP), all under the auspices of the World Climate Research Programme (WCRP). Computational support for the model runs was provided by the authors' institutions and associated funding agencies. Coordination of the results was supported by National Aeronautics and Space Administration Grant NAG5-11579.

\section{REFERENCES}

Berbery, E. H., Y. Luo, K. E. Mitchell, and A. K. Betts, 2003: Eta model estimated land surface processes and the hydrologic cycle of the Mississippi basin. J. Geophys. Res., 108, 8852, doi:10.1029/2002JD003192.

Best, M. J., A. Beljaars, J. Polcher, and P. Viterbo, 2004: A proposed structure for coupling tiled surface with the planetary boundary layer. J. Hydrometeor., 5, 1271-1278.

Betts, A. K., J. H. Ball, A. C. M. Beljaars, M. J. Miller, and P. Viterbo, 1996: The land surface-atmosphere interaction: A review based on observational and global modeling perspectives. J. Geophys. Res., 101, 7209-7225.

Dirmeyer, P. A., 1995: Meeting on problems in initializing soil wetness. Bull. Amer. Meteor. Soc., 76, 2234-2240.

- 2001: An evaluation of the strength of land-atmosphere coupling. J. Hydrometeor., 2, 329-344.

_ , F. J. Zeng, A. Ducharne, J. Morrill, and R. D. Koster, 2000: The sensitivity of surface fluxes to soil water content in three land surface schemes. J. Hydrometeor., 1, 121-134.

Douville, H., 2003: Assessing the influence of soil moisture on seasonal climate variability with AGCMs. J. Hydrometeor., 4, 1044-1066.

Eltahir, E. A. B., 1998: A soil moisture-rainfall feedback mechanism, 1. Theory and observations. Water Resour. Res., 34, 765-776.

Entekhabi, D., I. Rodriguez-Iturbe, and R. L. Bras, 1992: Variability in large-scale water balance with land surface-atmosphere interaction. J. Climate, 5, 798-813.

Findell, K. L., and E. A. B. Eltahir, 2003: Atmospheric controls on soil moisture-boundary layer interactions. Part II: Feedbacks within the continental United States. J. Hydrometeor., 4, 570583.

Koster, R. D., and M. J. Suarez, 2001: Soil moisture memory in climate models. J. Hydrometeor., 2, 558-570.

, P. A. Dirmeyer, A. N. Hahmann, R. Ijpelaar, L. Tyahla, P. Cox, and M. J. Suarez, 2002: Comparing the degree of landatmosphere interaction in four atmospheric general circulation models. J. Hydrometeor., 3, 363-375.

_ - and Coauthors, 2004: Regions of strong coupling between soil moisture and precipitation. Science, 305, 1138-1140.

- - and Coauthors, 2006: GLACE: The Global LandAtmosphere Coupling Experiment. Part I: Overview. J. Hydrometeor., 7, 590-610.

Lawrence, D. M., and J. M. Slingo, 2004a: An annual cycle of vegetation in a GCM. Part I: implementation and impact on evaporation. Climate Dyn., 22, 87-106.

- , and $-2004 \mathrm{~b}$ : An annual cycle of vegetation in a GCM. Part II: Global impacts on climate and hydrology. Climate Dyn., 22, 107-122.

Namias, J., 1960: Factors in the initiation, perpetuation and termination of drought. IASH Commission of Surface Waters Publication 51, 81-94.

Polcher, J., and Coauthors, 1998: A proposal for a general interface between land surface schemes and general circulation models. Global Planet. Change, 19, 261-276.

Schlosser, C. A., and P. C. D. Milly, 2002: A model-based investigation of soil moisture predictability and associated climate predictability. J. Hydrometeor., 3, 483-501. 